BENM 2021

International Scientific and Practical Conference "Biotechnology, Ecology, Nature Management"

\title{
FISH PROTECTION, IN RELATION TO THE HYDRAULIC STRUCTURES OF THE MOSCOW CANAL
}

\author{
A. V. Gorbunov (a)*, V. A. Klimov (b), T. L. Kalita (c), V. R. Barbashov (d) \\ *Corresponding author
}

(a) K.G. Razumovsky Moscow State University of Technologies and Management (the First Cossack University, 73, Zemlyanoy Val str., Moscow, Russia, akvabiotex@rambler.ru

(b) K.G. Razumovsky Moscow State University of Technologies and Management (the First Cossack University, 73, Zemlyanoy Val str., Moscow, Russia, mirvar@rambler.ru

(c) K.G. Razumovsky Moscow State University of Technologies and Management (the First Cossack University), 73, Zemlyanoy Val str., Moscow, Russia, t.kalita@mgutm.ru

(d) K.G. Razumovsky Moscow State University of Technologies and Management (the First Cossack University), 73, Zemlyanoy Val str., Moscow, Russia, vladimirbarbashov1995@gmail.com

\begin{abstract}
The purpose of the research is to establish functional characteristics for the Ivankovsky water intake, hydrological features of the hydroelectric power station water area, biological parameters of representative fish and to develop recommendations for fish protection for retrofitting this object, with a non-capital nature. The surveys were determined by the terms of reference for the contract, the biological parameters of representative species of ichthyofauna in the water area of this object. Ichthyological samples (control catches) were made according to the scheme: 2 double catches at the object: the 1 st-in the water intake zone; and the 2nd - on the border of the sanitary zone of the upper stream, in the period May-August. Dominant in number to the rest of the fish were: tyulka (Freshwater tyulka) is $82 \%$ in the water column and bream (Abramis brama) is almost $90 \%$ at the bottom, followed by gustera (Blicca bjoerkna) - in pelagial and at the bottom (7-10\%). Because of this, the RZS designed at the facility should mainly meet the conservation of Freshwater tyulka (Freshwater tyulka) and bream (Abramis brama). It is recommended to use complex reds according to the "input-action-output" scheme with the use of additional reds for environmental and behavioral protection methods: air-bubble curtains or electric fish barriers-focused on fry and fish up to 20-30 mm, when combined with mechanical fish protection for larger fish.
\end{abstract}

2672-8575 ㄷ 2022 Published by European Publisher.

Keywords: Ichthyofauna of the reservoir, Ivankovskaya HPP, fish protection, Open water intake 


\section{Introduction}

A group of specialists from the Institute of "Biotechnology and Fisheries" (BiRH), the Department of "Biology and Ichthyology" of the K. G. Razumovsky Moscow State Technical University (PKU) on the basis of an economic contract, conducted a number of scientific studies to study the impact of water intakes of existing hydraulic structures (GTS) of the Moscow Canal (5 objects in total) on the ichthyofauna of a water body, in order to determine the need for the arrangement of fish protection structures (RZS) and their functional technological type. These surveys, analysis and processing of the results were carried out at a number of hydraulic engineering facilities of the customer, in the periods from April to September from 2015 to 2020. This material presents some results on the topic "ecological and behavioral methods of fish protection, in relation to the hydraulic structures of the Moscow Canal, namely, the open water intake of the Ivankovskaya hydroelectric power station of the Volzhsky district of hydraulic structures (CSG). Ivankovskaya HPP is located in Dubna, Moscow Region, in the upper reaches of the Volga River. The dam raises the horizon of the Volga River by 11 meters and forms a reservoir with a water volume of 1 billion 120 million cubic meters. Along with this, the dam allowed to build a hydroelectric power station with a capacity of 30 thousand $\mathrm{kW}$.

Hydrological, hydromorphological, hydrothermal, hydrobiological and other processes developing in reservoirs differ significantly from similar processes in the conditions of watercourses. In most cases, they are individual, since they are primarily due to local topographic, meteorological, geological and other features of the selected section of the reservoir (Abakumov, 2000). The conditions of water intake from surface sources are divided depending on the stability of the banks and the source bed, channel, ice regimes and clogging. The studied water intake, according to the conditions of water intake, is characterized by us as"light".

The main provisions in the design and reconstruction of such GTS according to the requirements for environmental protection, are regulated by the Set of Rules of SP 58.13330.2012 " SNiP 33-01-2003. Hydraulic structures. Basic Provisions" (Ministry of Regional Development of the Russian Federation, 2011).

\section{Problem Statement}

The construction and operation of GTS, as a rule, causes a negative impact on the natural biological resources of water bodies, including the state of fish stocks (Gorbunov et al., 2013). When understanding the influence of hydraulic structures on the hydrobiological regime of a watercourse, it should be borne in mind that watercourses are a complex self-reproducing ecosystem with homeostasis, i.e. the ability to resist the disturbing influence of external abiotic factors. This property of aquatic ecosystems is provided by direct and inverse connections (energy and information) of inorganic and biotic components (Mikheev et al., 2009).

The preservation of such homeostasis (hydrobiocenosis) is possible only within certain limits of changes in external abiotic factors-the limits of the system's resistance (resistance). If the factor goes beyond these limits, it leads to the death of the ecosystem. The long-term existence of an ecosystem near the upper or lower limit of resistance leads to its gradual degradation and, ultimately, to death. The 
functioning of waterworks leads to a violation of the homeostasis of the ecosystem. In the upper reaches, the river, as an ecosystem, is completely destroyed, and in its place a new natural and technical anthropogenic hydraulic system is formed, which has not yet become an ecosystem and, accordingly, does not have the properties of self-reproduction and homeostasis (Gorbunnov \& Kozlov, 2019).

When designing and reconstructing the GTS, according to the existing procedure, an environmental assessment (EIA) is carried out, in which the consequences of its impact on the biosphere are predicted, for which the boundaries of water bodies are determined, in the water area of which it is worth expecting a negative impact on bioresources. The safety criteria and their quantitative indicators should be reviewed at least once every 5 years (The Government of the Russian Federation, 2008).

Within such water areas:

- location, boundaries, areas and productivity of spawning grounds, indicating the species composition of spawning commercial fish and spawning dates;

- juvenile fish places of concentration of juveniles with indication of their boundaries, area, as well as species composition, periods of hatching of juveniles and its concentration per unit volume of water;

- migration routes of spawning and passing fish with indication of migration dates and the species composition of migrants;

These data constitute the fisheries characteristics of the water body and (or) its site, they are developed by the responsible organizations of Rosrybolovstvo on the basis of the materials of the state accounting or the fisheries cadastre of the water body; in their absence, special studies are conducted.

To reduce the negative impact of the projected object, the nature and degree of influence of each factor (from among the considered ones) on the conditions for the formation of fish stocks of the water body, taking into account their state at the time of design, is determined; qualitative and quantitative damage to the animal world within the territory of the influence of the hydroelectric Based on this, the composition and volume of necessary fish protection or restoration measures are assigned (Gorbunnov \& Kozlov, 2019).

Quantitative damage to the animal world is the influence of hydro-engineering on the circulation of matter in ecosystems due to the removal of a certain animal biomass as a component of natural complexes. Indicators of quantitative damage are

- complete removal of a part of the population of species that inhabited the zones of flooding, processing of the banks and severe flooding of the reservoir;

- small quantity of secondary products in the form of young individuals.

The damage is estimated in natural units, taking into account the species and its ontogenetic parameters. The quantitative side of the damage can also be represented in value terms. The cost estimate of biomass is given for various groups of animals and reflects their consumer value, depending on the economic use, the value for the economy, and other legally established parameters.

Qualitative damage to the animal world can be expressed only in ecological terms, it consists in the violation of the biodiversity of communities, namely:

- in the reduction of species diversity;

- in changing the structure of communities; 
- in the transition of mass and common species to the category of rare and endangered.

Thus, environmental methods of fish protection, including behavioral ones, in relation to hydraulic structures, are the most important and fundamental qualitative component of the well-being of the hydroecosystem of the GTS location and its biocenoses (Gorbunov et al., 2013).

\section{Research Questions}

In accordance with the task for scientific research, ichthyological studies of the object were provided for the purpose of hydrobiological justification of the development of effective fish protection for it and the determination of its technological type, taking into account the characteristic bioecological features of the water intake, ichthyological parameters, its water area and hydrological regimes of the water area of this hydroelectric unit. When designing fish protection devices at the facility, along with technical ones, it is also necessary to take into account the following biological characteristics of ichthyocenosis in the behavior of fish and juveniles of its representative species:

- reoreaction - the orientation of the fish's head to the current and movement against the water flow. Active and passive migrations, nutrition, protection from predators, some mechanisms of gregarious behavior, etc. are associated with it in fish

- vision is a reception well developed in most freshwater and passing fish, with the exception of sturgeon and some nocturnal predators (catfish, burbot);

- hearing-fish hear in a wide sound range from 16 to $5000 \mathrm{~Hz}$, and in some cases up to $13,000 \mathrm{~Hz}$. Fish do not perceive high sound and ultrasonic frequencies by hearing;

- the lateral line organs are - the receptor by which fish perceive mainly the low part of sound vibrations with a frequency from 1 to $25 \mathrm{~Hz}$, hydrodynamic fields and water jets; this is important when fish are oriented in streams with increased turbulence;

- Chemoreception - is associated with extremely sensitive organs of smell and taste. The organs of smell are used by fish for signaling, detecting predators and food, and the organs of taste - in search of food.

The above-mentioned biological species characteristics of fish are either the subject of research (Yarovikov, 2017) in relation to a specific one object and the type of possible fish protection, in relation to a hydraulic structure, or these characteristics can be reasonably recommended by the manufacturer of mass-produced fish protection devices.

The research objectives also included monitoring the critical ecological and anthropogenic parameters of this hydraulic structure for the surrounding hydrobiocenosis, for which it was necessary to conduct a screening analysis of the sanitary protection zone of the object, in order to substantiate and develop appropriate ecological and technical recommendations for the object of study in connection with the protection of local ichthyofauna. The planned fish protection of the water intake, which is planned for use, should be considered in several directions:

The 1st direction - provides for the choice of the correct location of water intakes and their water intakes and is associated with the peculiarities of the distribution of juveniles, their migration, seasonal and daily rhythm of ingress in this particular reservoir and watercourse. The area with the minimum concentration of fish for the water intake device is determined; 
The 2nd direction - is related to the protection of fish that have fallen into the area of water intakes, and is based on knowledge of the methods of controlling the behavior of fish, their reactions to individual stimuli used to scare away or the direction of movement of juveniles, as well as knowledge of the speeds of movement of fish.

The seasonal rhythm of getting young fish into water intakes is quite different in different reservoirs and watercourses, and can change over the years. The most dramatic increase in the concentration of juveniles in the water intake area usually occurs as a result of previous spawning of producers or migration of juvenile fish - which also needs to be taken into account when developing recommendations on the applicability of certain fish protection technologies at a particular facility.

\section{Purpose of the Study}

The GTS of the Moscow Canal are capital strategic objects (Terekova \& Terekov, 2017), which regulate the levels of several navigable rivers and are burdened with a special protection regime. Built more than half a century ago, specialized fish protection systems were not provided for in their composition, but at the same time it is a necessity. Fish protection means (systems and devices) are of particular relevance, taking into account the functional features of the object, the hydrological features of the water area and adapted in efficiency to the biological parameters of representative species of the ichthyofauna of this water body, with which it is possible to retrofit this object without resorting to capital measures. It was the development of such scientific recommendations that was the main goal of our research.

\section{Research Methods}

The conducted surveys were carried out in accordance with the terms of reference for the contract, determined by the customer at the actual facility for the biological parameters of representative species of ichthyofauna of this water body, determining the effectiveness of the applied fish protection, and had an applied orientation, therefore, statistical processing of the data obtained (meta-analysis) was not carried out.

The main source of ichthyological materials in these surveys are catches. In small and other reservoirs where there is no regular fishing, ichthyological materials are collected during the control fishing of the reservoir. The state of stocks of a particular fish in a reservoir is judged, first of all, by the size of catches, the quantitative ratio of species groups, the growth of fish (morphometry).

When choosing and using fishing gear, it is necessary that they correspond to the task at hand. First, an assessment is made of the applicability of this fishing gear to the intended object of study; the fishing gear must also correspond to the habitats of the object of study. Secondly, the time of collecting the material is taken into account; it must be remembered that all fishing gear has one or another selectivity, that is, they make a certain systematic error in creating a sample of individuals from the general population.

In this case, due to the specifics of the GTS objects and their special regime zone, fishing rods, set nets/seines, traps are possible for use (with the permission of the Moscow-Oka Territorial Administration 
of the Federal Agency for Fisheries of the Ministry of Agriculture of the Russian Federation, departments of state control, supervision, protection of aquatic biological resources and their habitat in the city of Moscow and MO - fishing rods, set nets / seines, traps - depending on the tasks set, the objects of research, the complexity and specifics of the water area of the water intake of the object and temporary seasonal and climatic conditions of field research.

During the field research, ichthyological samples (research catches) were carried out according to the scheme: 2 double catches at the facility [1st: in the water intake zone; and 2nd: on the border of the sanitary zone of the upper stream, in the period: May-August. Research and processing of ichthyological material was carried out according to generally accepted methods, the data of control catches (samples) were entered in tables for the object, in the final tables for the hydroelectric unit - were averaged.

Morphological studies. A morphological description of the fish is given for its left side, with asymmetry, the structural features of the right side of the fish are given. The description of the fish begins by indicating the general shape of the body and the ratio of the size of the head to the rest of the body (Zinoviev \& Mandritsa, 2003).

Morphometric studies. With the help of a caliper, measurements of the fish under study are made. Sometimes a centimeter tape is used to measure the girth of the fish. All fish have three main parts of the body: the head, trunk and tail. The external border between the head and the trunk is the posterior edge of the gill cover, between the trunk and the tail is the anal opening. When describing the head, its approximate relative size is indicated, and when studying the eyes, it is necessary to specify their relative size and position on the head. For fish measurements, symbols are used in the form of capital letters of Latin names (Pravdin, 1966):

- the total length of the fish from the mouth to the end of the caudal fin (AB), cm

- the commercial length of the fish from the end of the mouth to the end of the scale cover (AD), $\mathrm{cm}$

- the length of the fish from the end of the mouth to the recess of the caudal fin (AC), in $\mathrm{cm}$

- total weight of fish with entrails (M), g

- Maximum body thickness (Tmax)

- Maximum body height (Hmax);

- minimum body height (Hmin).

\section{Findings}

To assess the dangers for the VBR, it is important to know the fishing value of the reservoir for the national economy. For an objective assessment, in addition to our own data, we also used the materials of other researchers. The reservoir is eutrophic in terms of water quality relative to the VBR, with marked winter freezes.

The ichthyofauna in the reservoir was formed mainly due to the Volga basin, there were 33 species of fish in it, according to various data - the main species - only 12 species (Solomatin \& Bazarov, 2014). In 2012-2013, bream (Abramis brama) remained valuable and numerous commercial fish, with gustera (Blicca bjoerkna) in second place. The remaining types occupied 4-5\%. 
According to the biomass, the basis of the Ivankovsky reservoir today is formed by 4 species: tyulka (Freshwater tyulka), bream (Abramis brama), roach (Rulilus rutilus) and gustera (Blicca bjoerkna). The control catches carried out showed that the ratio of fish in the pelagial of the Ivankovsky reservoir today is as follows: gustera (Blicca bjoerkna) - 35\%, bream (Abramis brama) $-34 \%$, roach (Rulilus rutilus) - 14\%, tyulka (Freshwater tyulka) - 7\%, chehon (Pelecus cultratus) - 6\% and other species $-4 \%$.

During the control catches, the most significant numbers were present: tyulka (Freshwater tyulka) - in pelagial, bream (Abramis brama) and gaster (Blicca bjoerkna) - in the bottom horizon. In addition to the Freshwater tyulka, perch (Perca fluviatilis) and bleak (Alburnus alburnus) are common in pelagial, and river catfish (Silurus glanis (L.)) are common in bottom trawls. Below (Table 1) is the size composition of the main representative fish species recorded by us at the Ivankovsky reservoir in the area of the object of study.

Table 1. Average sizes of representative fish of the Ivankovsky reservoir in control net catches in the HPP zone

\begin{tabular}{ccc}
\hline Fish & Predominant group, cm & Fraction, $\mathbf{\%}$ \\
\hline Tyulka (Freshwater tyulka) & $3,7-6,5$ & $80-85$ \\
Bream (Abramis brama) & $19,0-29,0$ & $70-73$ \\
Gustera (Blicca bjoerkna) & $14,5-19,5$ & $60-65$ \\
\hline
\end{tabular}

Studies conducted earlier (Solomatin \& Bazarov, 2014) show that in the reservoir the dominant numbers are: in the pelagial - tyulka (Freshwater tyulka), and at the bottom - bream (Abramis brama) Table 2.

Table 2. Density and ratio of species in control catches at the Ivankovsky reservoir 2013-2014

\begin{tabular}{ccccc}
\hline Fish & $\begin{array}{c}\text { Average quantity in } \\
\text { pelagial, pcs }\end{array}$ & $\mathbf{\%}$ & $\begin{array}{c}\text { Average quantity } \\
\text { at the bottom, pcs }\end{array}$ & $\%$ \\
\hline Tyulka (Freshwater tyulka) & 191 & 82 & 0 & 0 \\
Gustera (Blicca bjoerkna) & 17 & 7 & 25 & 10 \\
Bream (Abramis brama) & 12 & 5 & 229 & 88 \\
Roach (Rutilus rutilus) & 7 & 3 & 0 & 0 \\
Other types & - & 2 & - & 2 \\
\hline
\end{tabular}

The ratio of tyulka (Freshwater tyulka) is $82 \%$ to the rest of the fish in the water column, and bream (Abramis brama) is almost 90\% at the bottom. Therefore, the fish protection device designed at this facility should meet the requirements for the conservation of mainly tyulka (Freshwater tyulka) and bream (Abramis brama); in second place in terms of population density, there is a gustera (Blicca bjoerkna) in pelagial and near the bottom (7-10\%).

Calculations of the biomass $(\mathrm{kg})$ of 12 species and subspecies of fish were made in terms of 1 ha of the reservoir (Table 3). The maximum biomass in the pelagial is occupied by 3 species - gustera (Blicca bjoerkna), bream (Abramis brama) and roach (Rulilus rutilus), and only in the 4th place was the tyulka (Freshwater tyulka) $-7.3 \%(0.4 \mathrm{~kg} / \mathrm{ha})$. 
Table 3. Ichthyomass of the main fish species of the Ivankovsky reservoir in the HPP zone

\begin{tabular}{ccccc}
\hline Fish & $\begin{array}{c}\text { Ichthyomass in } \\
\text { pelagial, kg/ha }\end{array}$ & $\mathbf{\%}$ & $\begin{array}{c}\text { Ichthyomass at the } \\
\text { bottom, kg/ha }\end{array}$ & $\%$ \\
\hline Tyulka (Freshwater tyulka) & 0,4 & 7,3 & 0 & 0 \\
Bream (Abramis brama) & 1,8 & 32,0 & 67,6 & 93,3 \\
Roach (Rutilus rutilus) & 0,7 & 12,6 & 0,1 & 0,2 \\
Gustera (Blicca bjoerkna) & 2,0 & 36,2 & 3,0 & 4,2 \\
\hline
\end{tabular}

At different times of their life in reservoirs, fish occupy a particular ecological niche, depending on the type and age, which must be taken into account when designing the RZS. So, during the control fishing, it was found that bream (Abramis brama) - $93.3(67.6 \mathrm{~kg} / \mathrm{ha})$ and a small amount of $4.2 \%(3$ $\mathrm{kg} / \mathrm{ha}$ ) - gaster (Blicca bjoerkna) dominated at the bottom. With a total ichthyomass of $77.5 \mathrm{~kg} / \mathrm{ha}$, bottom fish products, despite the dominance of Freshwater tyulka, exceeded the biomass of fish living in the pelagial by more than $90 \%$.

It should also be taken into account that it is quite difficult to prevent fish from entering the water intakes of HPP turbines and the spillways of the dam at the stages from caviar to fry. Juveniles can enter the water intakes of the GTS at different times of the day with seasonal rhythmicity. When determining the effectiveness of the RRS at this facility, it is necessary to be guided by the biologicalbehavioral and morphometric features, first of all, of the main representative species of VBR present within and on the border of the water intake area (Table 4): Tyulka (Freshwater tyulka), Bream (Abramis brama), Roach (Rutilus rutilus), Gustera (Blicca bjoerkna).

Table 4. Averaged data of biological and morphometric analysis of control samples of VBR in the vicinity of the water intake of the Ivankovskaya HPP (according to Pravdin, 1966)

\begin{tabular}{cccccccc}
\hline Type of fish & $\begin{array}{c}\text { Individuals, } \\
\text { pcs }\end{array}$ & ABcp & ACcp & ADcp & Mcp & Tmax & Hmax \\
\hline $\begin{array}{c}\text { Tyulka } \\
\text { (Freshwater tyulka) }\end{array}$ & 190 & 7,5 & 6,2 & 5,8 & 13,5 & 0,8 & 2,5 \\
$\begin{array}{c}\text { Gustera } \\
\text { (Blicca bjoerkna) } \\
\text { Bream }\end{array}$ & 17 & 26,9 & 23,4 & 22,0 & 235,0 & 2,2 & 8,0 \\
$\begin{array}{c}\text { (Abramis brama) } \\
\text { Catfish }\end{array}$ & 12 & 37,9 & 31,7 & 29,6 & 601 & 1,7 & 11,4 \\
(Silurus glanis (L.)) & 6 & 39,1 & 37,2 & 36,9 & 397 & 9,3 & 6,3 \\
\hline
\end{tabular}

Based on the analysis of all available and received data, as well as SP 101.13330.2012 (Ministry of Regional Development of the Russian Federation, 2012), at the Ivankovskaya HPP, having a head of $13 \mathrm{~m}$, a ladder fish walker should be used, a fish lifter (hydraulic or mechanical) that is part of the pressure front of the hydraulic unit and a fish accumulator (stationary or floating) that is not part of the pressure front of the hydraulic unit with fishing vehicles equipped with atraumatic fishing gear.

In the case of using a different type of RSL structures, including those based on ecological and behavioral methods, it is necessary to be guided by the principles of three-stage protection of the VBR according to the "Input-action-output" scheme, using a multicomponent fish protection system as part of the RSL, including three main sequentially arranged functional elements:

- input flow-forming; 
- working protective-water intake;

- output fish outlet:

- additional auxiliary element (if appropriate): orienting, attracting, scaring.

As recommended alternative reds for this object, requiring, however, coordination and confirmation of effectiveness on the spot, we can recommend considering a comprehensive REDS with the use of ecological and behavioral methods of protection: air-bubble curtains, acoustic or electric fish barriers-focused primarily on fry and fish up to $20-30 \mathrm{~mm}$, however, they should be combined with mechanical fish protection focused on larger objects more than $40 \mathrm{~mm}$, which can be successfully used on large, water intakes.

When using ecological and behavioral methods of protection combined with a "water-air curtain", it is necessary to constructively provide for the use of an auxiliary fish drainage system that redirects the raised young into the transit stream. This fish protection system for effective operation will require engineering and technological solutions tied directly to this object and mandatory compliance with the parameters provided for by the design of the individual components of the RZ-system, the actual location of the placement, and the provided operating conditions.

\section{Conclusion}

The fish protection structure should include the following main functional elements: an input head, a fish passage path, devices for extinguishing excess flow energy in the fish passage path, an upper head with a counting device, a power supply unit. On water bodies of fisheries significance, including those with a diverse species composition of the ichthyofauna, and with a cascade arrangement of waterworks, it is mandatory to use fish-lifting structures, in other cases - fish-moving ones. The location of the RZ at the GTS facility, which have a capital character, is determined strictly by the project documentation, made in accordance with the requirements established for these facilities.

It is necessary to note special caution on the application of various systems and other principles on the capital GTS of the Russian Federation, which are not indicated in the joint venture 101.13330.2012, the projects and technologies being implemented of which must be approved for use by the Federal Agency for Fisheries of the Ministry of Agriculture of the Russian Federation (Rosrybolovstvo of the Ministry of Agriculture of the Russian Federation, 2013), since they are not approved and recommended by the set of rules for the design of the GTS. At the same time, their effectiveness for a particular object must be confirmed directly on the spot during operation and, if it does not meet the standard (the effectiveness of fish protection structures for fish with a size of $12 \mathrm{~mm}$ and above should be at least $70 \%$ ), then the owner of the GTS has direct losses, with the subsequent design and creation of new, more effective ROMs (Federal Agency for Fisheries, 2009).

It is also advisable to implement preventive measures aimed at preventing fish and other aquatic biological resources from entering water intake structures by ecological landscape correction of local sections of the reservoir (Ivanov, 2021) - the creation of artificial reefs, depending on the hydrological characteristics of the water body, it is possible to use both bottom and pelagic reefs located in the characteristic layers and sections of the reservoir that are most attractive for fish. 
The design of a multicomponent fish protection structure should be developed by combining individual interconnected and mutually complementary functional elements. From the variety of each of them, it is necessary to choose the most compatible structures with each other, the principles of joint action of which are most suitable for the conditions of a particular object. After that, combining the selected designs of functional elements within a three-component complex and supplementing them, if necessary, with auxiliary elements, it is necessary to make a design of a fish protection structure that is optimal for the conditions of a particular object.

\section{References}

Abakumov, V. A. (2000). Ivankovskoe reservoir. The current state and the problem of protection. Science.

Federal Agency for Fisheries. (2009). Order of the FAR No. 786. Instructions on the procedure for monitoring the effectiveness of fish protection devices and monitoring the death of fish at water intake facilities. Rossiyskaya Gazeta.

Gorbunnov, A. V., \& Kozlov, A. V. (2019). Fisheries hydraulic engineering. textbook for bachelors in the direction of "Aquatic bioresources and aquaculture". - M.: MGUTU, 2019. - 185c, 185. MGUTU.

Gorbunov, A. V., Gorbunov, O. V., Borodin, A. L., \& Ridiger, A. V. (2013). Characteristic features of freshwater ichthyocenosis of a model reservoir of a regulated type. The journal "Fisheries", 4, 7477.

Ivanov, A. A. (2021). A nature-like technology for protecting fish at a hydroelectric power station. Proceedings of the All-Russian Research Institute of Hydraulic Engineering named after B. E. Vedeneev, 299, 77-76.

Mikheev, V. P., Bagrov, D. A., Mikheeva, I. V., \& Pechenin, A. I. (2009). Water bioresources of reservoirs of the watershed of the Moscow canal. VNIIPRH.

Ministry of Regional Development of the Russian Federation. (2011). The Code of Rules of the Joint Venture 58.13330.2012. Hydraulic structures. The main provisions, with amendments and additions. from 20.10.2016. Ministry of Regional Development of the Russian Federation, Order No. 623 of 29.12 .2011 .

Ministry of Regional Development of the Russian Federation. (2012). The code of rules of the Joint venture 101.13330.2012. SNiP 2.06.07-87 Retaining walls, navigable locks, fish-passing and fishprotection structures. Ministry of Regional Development of the Russian Federation.

Pravdin, I. F. (1966). Guide to the study of fish (ed. 4th revised and supplemented). (V. V. Deryagin, \& P. A. Pokrovsky, Ed.). Food Industry.

Rosrybolovstvo of the Ministry of Agriculture of the Russian Federation. (2013). Decree of the Government of the Russian Federation No. 384. On the approval of the FAR for the construction and reconstruction of capital construction facilities, the introduction of new technological processes and the implementation of other activities that affect the VBR and their habitat. M: FAR of the Ministry OF Agriculture OF the Russian Federation.

Solomatin, Yu. I., \& Bazarov, M. I. (2014). The density of the fish population and its species diversity in the channel areas of the Ivankovsky reservoir in 2012-2013. The current state of bioresources of inland waters, T2, 535-541.

Terekova, I. A., \& Terekov, A. S. (2017). Overview of the designs of the main types of fish protection devices. In Collection of materials of the International scientific and practical Conference "New information technologies in science". (pp. 133-137). International Research Agency.

The Government of the Russian Federation. (2008). Resolution No. 569. Rules for coordinating the placement of economic and other objects, as well as the introduction of new technological processes that affect the state of aquatic biological resources and their habitat. Collection of legislation of the Russian Federation, 31, 3740, 10178-10180. 
Yarovikov, I. V. (2017). Fish protection device for water intakes. Zh-l "Engineering personnel - the future of the innovative economy of Russia". 5. PSTU.

Zinoviev, M. A., \& Mandritsa, M. A. (2003). Special course. Methods of freshwater fish research: $A$ textbook for a special course, 113. 